\title{
ARTICLE
}

Epidemiology

\section{Bisphosphonates and risk of cancers: a systematic review and meta-analysis}

\author{
Yuan-Yuan Li ${ }^{1}$, Li-Jie Gao ${ }^{1}$, Yu-Xue Zhang ${ }^{2}$, Shu-Juan Liu ${ }^{1}$, Shuo Cheng ${ }^{1}$, Yu-Peng Liu ${ }^{3}$ and Cun-Xian Jia (DD ${ }^{1}$
}

BACKGROUND: It is unclear whether bisphosphonates are associated with risk of cancers. Therefore, this meta-analysis aimed to evaluate the effect of bisphosphonates on overall cancers.

METHODS: A search in Pubmed, Embase, Cochrane Library and Web of Science databases was conducted, from the inception date of each resource to September 26,2019 . The summarised effect estimates with $95 \%$ Cls were calculated using a random-effect model. Heterogeneity and publication bias were explored.

RESULTS: Thirty-four articles were included in this study (4,508,261 participants; 403,196 cases). The results revealed that bisphosphonates significantly decreased the risk of colorectal cancer (RR $=0.89,95 \% \mathrm{Cl}: 0.81-0.98)$, breast cancer $(\mathrm{RR}=0.87,95 \%$ $\mathrm{Cl}: 0.82-0.93)$ and endometrial cancer ( $\mathrm{RR}=0.75,95 \% \mathrm{Cl}: 0.61-0.94)$, but no significant association was observed in all-cause cancer. Furthermore, nitrogen-containing bisphosphonates only had protective effects both on breast cancer ( $\mathrm{RR}=0.94,95 \% \mathrm{Cl}$ : 0.90-0.99) and endometrial cancer ( $R R=0.70,95 \% \mathrm{Cl}$ : 0.54-0.92). Non-nitrogen-containing bisphosphonates tended to increase the risk of liver cancer $(\mathrm{RR}=2.14,95 \% \mathrm{Cl}: 1.23-3.72)$ and pancreas cancer $(\mathrm{RR}=1.75,95 \% \mathrm{Cl}: 1.32-2.33)$.

CONCLUSION: Bisphosphonates are significantly associated with risk reduction of colorectal, breast and endometrial cancer, especially nitrogen-containing bisphosphonates. It should be noted that non-nitrogen-containing bisphosphonates might increase the risk of liver and pancreas cancer. Large prospective cohort studies are needed to find the causal association between bisphosphonates and risk of cancers.

British Journal of Cancer (2020) 123:1570-1581; https://doi.org/10.1038/s41416-020-01043-9

\section{BACKGROUND}

Cancer is an important public health problem in the world, and the incidence and mortality of global cancer have grown rapidly in recent years. ${ }^{1}$ According to the Global Burden of Disease study (GBD) 2017, the most common incident cancers were non-melanoma skin cancer (NMSC, 7.7 million incident cases), tracheal, bronchus and lung (TBL) cancer (2.2 million incident cases), breast cancer (2.0 million incident cases) and colorectal cancer (1.8 million incident cases). ${ }^{2}$ In terms of women, breast cancer was the most commonly diagnosed cancer, followed by colorectal, lung and cervical cancer. ${ }^{3}$ Prevention of cancers has become a great public health importance.

In recent years, preclinical studies have suggested that bisphosphonates have direct and indirect antitumour properties, including inhibition of tumour cell adhesion and proliferation, 4,5 induction apoptosis of tumour cells, ${ }^{6}$ prevention of angiogenesis ${ }^{7,8}$ as well as activation of immune cells. ${ }^{9}$ Wysowski et al. ${ }^{10}$ reported that the US Food and Drug Administration (FDA) received 23 cases of oesophageal cancer after the use of bisphosphonates. Since then, some epidemiological studies were also conducted on the association between bisphosphonates and the risk of some types of cancers, but the results of these studies were controversial. ${ }^{11-14}$ To date, most meta-analyses were focused on the association between the use of bisphosphonates and the risk of some specific types of cancers. ${ }^{15-24}$ For instance, Yang et al. ${ }^{19}$ suggested that the use of bisphosphonates might decrease the risk of colorectal cancer by $11 \%(\mathrm{RR}=0.89,95 \% \mathrm{Cl}: 0.80-0.99)$, while $\mathrm{Oh}$ et al. ${ }^{25}$ found no significant association between the use of bisphosphonates and colorectal cancer ( $R R=0.62,95 \% \mathrm{Cl}: 0.30-1.29)$. To the best of our knowledge, there was currently only one metaanalysis by Deng et al. ${ }^{26}$ on the use of bisphosphonates and the risk of all-cause cancers, which only included 13 cohort studies and analysed the association in mixed genders and females.

Bisphosphonates are widely prescribed for preventing and treating osteoporosis, 27,28 but the number of bisphosphonate users is expected to increase globally. For example, in the United States alone, there are approximately 40 million bisphosphonate prescriptions each year. Considering the widespread use of bisphosphonates, it is essential to explore the association between bisphosphonates and cancers.

This systematic review and meta-analysis was intended to (1) analyse possible association between the use of bisphosphonates and the risk of overall cancers and individual types of cancers based on observational studies, (2) stratify analysis by different types and duration of bisphosphonates.

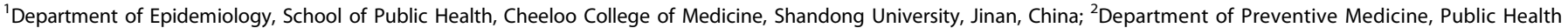

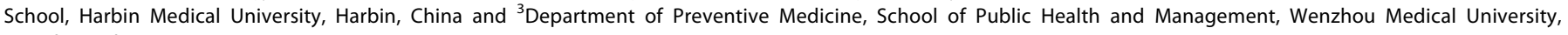
Wenzhou, China

Correspondence: Yu-Peng Liu (liuyupeng@wmu.edu.cn) or Cun-Xian Jia (jiacunxian@sdu.edu.cn)

These authors contributed equally: Yu-Peng Liu, Cun-Xian Jia

Received: 13 February 2020 Revised: 28 July 2020 Accepted: 14 August 2020

Published online: 9 September 2020 


\section{METHODS}

Literature search

This systematic review and meta-analysis was conducted following the PRISMA guidelines. ${ }^{29}$ We firstly searched relevant studies in the databases of Pubmed, Embase, Cochrane Library and Web of Science from the inception date of each resource to September 26, 2019, by two study investigators ( $\mathrm{Li}$ and Cheng) independently. Detailed search terms were shown in Supplementary Table S1. Then, before the statistical analysis of the data, we manually searched from lists of references cited by the published studies, or updated our studies from other sources upto December 7, 2019, to identify whether there was new literature published (PROSPERO registration number is CRD4-2014014901).

\section{Selection criteria}

The selection criteria of this meta-analysis were composed of inclusion and exclusion criteria. Studies were included in this meta-analysis if they complied with the following criteria:

(1) Study design was observational study (cohort study, case-control study, nested case-control study or case cohort study) addressing the association between the use of bisphosphonates and risk of any type of cancers

(2) The exposure was defined as one or more prescriptions of bisphosphonates

(3) The outcome was the incidence of cancers

(4) Studies reported effect estimates, including odds ratios (ORs), relative risks (RRs) or hazard ratios (HRs) with $95 \%$ confidence intervals (Cls), or provided sufficient data to calculate them

(5) If there were duplicate articles, the most recent published or the most complete data would be included

(6) Language was restricted to English.

Accordingly, these studies were excluded:

(1) Cross-sectional studies, reviews, comments or conference abstracts

(2) Studies were in vitro or animal experiments

(3) Studies without enough data to calculate the effect estimates

Data extraction and quality assessment

Data extraction and quality assessment were independently implemented by two researchers (Li and Liu) by using standardised forms, and any disagreement was resolved through discussion until consensus was reached. The following information was extracted from each study: first author, year of publication, population location, study design, study period, sample size, the number of cases, participants' age and sex, type and duration of bisphosphonates, type of cancers, adjusted confounding factors and the available effect estimates with the corresponding $95 \% \mathrm{Cls}$. The original authors of studies would be contacted, if the required information was missing.

The quality of each included study was assessed using the Newcastle-Ottawa Scale (NOS). ${ }^{30}$ The NOS assessed quality from the following three aspects: selection, comparability and exposure (case-control studies) or outcome (cohort studies). The total score of NOS was nine stars. Studies with a score of more than 6 stars were considered as relatively high quality. Conversely, studies with a score of less than 6 stars were considered as relatively low quality.

Data synthesis and analysis

RRs were often used as indicators to assess the association between the use of bisphosphonates and risk of cancers, and HRs were similar to RRs. We pooled the risk estimates of case-control and cohort studies in the primary meta-analysis because ORs and RRs could provide similar risk estimates when the outcomes were rare. $^{31}$ The maximally adjusted risk estimates with 95\% Cls were pooled by using random-effect models to obtain a more conservative outcome. Then, the heterogeneity among studies was evaluated by using the Cochrane's $Q$ statistic and the $I^{2}$ statistic. $^{32}$ The low, moderate and high degrees of heterogeneity in this study corresponding to that of the $I^{2}$ cut-offs were $25 \%$, $50 \%$ and $75 \%$, respectively.

To explore the sources of heterogeneity among studies, random-effect meta-regression analysis based on the residual maximum likelihood (REML) method and subgroup analysis for allcause cancers were conducted by study design, population region and sample size. According to the different molecular modes, bisphosphonates were classified into two groups, including nitrogen-containing bisphosphonates (such as alendronate, ibandronate, pamidronate, risedronate and zoledronate) and nonnitrogen-containing bisphosphonates (such as clodronate and etidronate). ${ }^{33}$ Then, the subgroup analysis was carried out to study the association between the use of bisphosphonates and various types of cancers based on different types (nitrogen- and nonnitrogen-containing bisphosphonates) and duration ( $<1$ year and $\geq 1$ year) of bisphosphonates.

The sensitivity analysis was performed by omitting one study and calculating the pooled risk estimates with $95 \% \mathrm{Cls}$ of the remaining studies. Furthermore, the potential publication bias was evaluated with funnel plots, ${ }^{34}$ and was quantitatively examined by Egger's linear regression tests. ${ }^{35}$ If there was publication bias, we would adjust the effect by using the trim-and-fill method. ${ }^{36}$ For statistical tests, a two-sided $P<0.05$ was considered statistically significant. All statistical analyses were performed using STATA version 15.1 (Stata Corporation, College Station, TX, USA).

\section{RESULTS}

Literature search and study characteristics

The flow diagram describing detailed literature searches and selection process is shown in Fig. 1. In brief, we identified 45,396 articles through systemically searching in the databases, of which 34 eligible articles (16 cohort studies, ${ }^{11,13,14,37-49} 11$ nested case-control studies, ${ }^{12,50-59} 6$ case-control studies ${ }^{60-65}$ and 1 case cohort study ${ }^{66}$ ) were included in the current meta-analysis.

The main characteristics of the included studies are summarised in Table 1. In total, 14 researches originated from Europe, 12 from America and 8 from Asia. Most of the papers (21/34) were published from 2010 to 2013. Of these, the data were available from 4,508,261 participants, including 403,196 cases originating from 19 types of cancers. Some articles focused on multiple types of cancers: 24 papers reported gastrointestinal cancers (stomach, small bowel, colon and rectum), 16 papers reported gynaecological cancers (endometrium, cervix and ovary), 14 papers reported oesophageal cancer, 10 papers reported breast cancer, 7 papers reported hepatobiliary cancers (liver and bladder), 5 papers reported lung cancer, 3 papers reported prostate cancer and 14 papers reported other cancers. Most of the participants were women, and the mean age ranged from 54.5 to 74.3 years. These studies indicated that alendronate was one of the most commonly used bisphosphonates. In addition, all studies adjusted confounding factors, and the quality assessment of the overall studies was high. Details of the adjusted confounding factors and quality assessment can be seen in Supplementary Tables S2-S4.

Bisphosphonates and risk of cancers

Fig. 2 shows the association between the use of bisphosphonates and risk of different types of cancers. Based on the estimates of the random-effect model, for specific types of cancers, the use of bisphosphonates was strongly associated with colorectal cancer (pooled $\mathrm{RR}=0.89,95 \% \mathrm{Cl}: 0.81-0.98, P=0.02$ ), breast cancer (pooled RR $=0.87,95 \% \mathrm{Cl}: 0.82-0.93, P<0.01$ ) and endometrial cancer (pooled RR $=0.75,95 \% \mathrm{Cl}: 0.61-0.94, P=0.01$ ). There was 


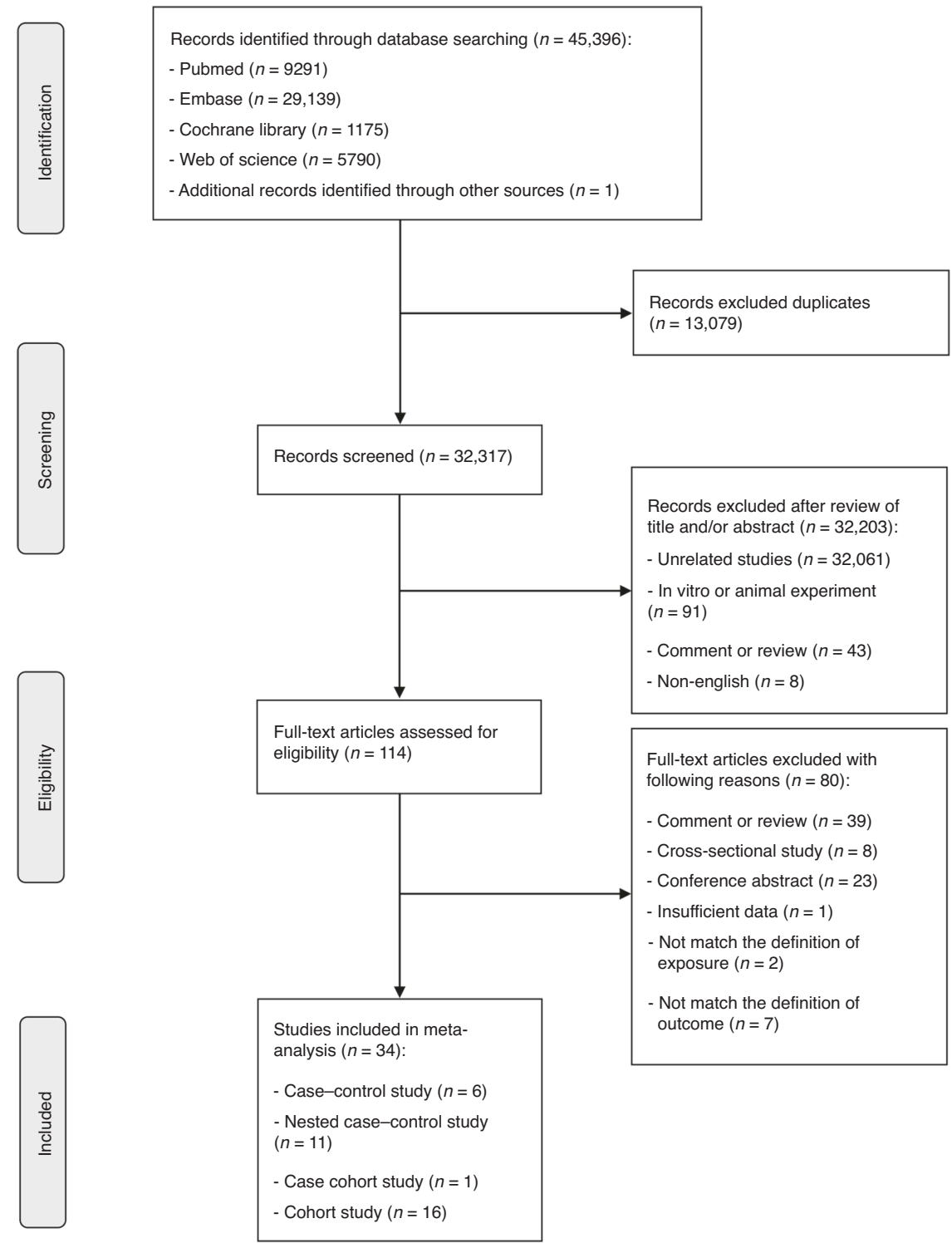

Fig. 1 Flow diagram of study selection in this meta-analysis. The update search was carried out on December 7, 2019, also manually searched lists of references cited by the published studies to examine for any additional studies reporting primary data.

no statistically significant association between the use of bisphosphonates and oesophageal cancer (pooled $\mathrm{RR}=1.13,95 \% \mathrm{Cl}$ : $0.98-1.31, P=0.10)$ as well as other types of cancers. The heterogeneity between studies was high in colorectal cancer $\left(P<0.01, l^{2}=80 \%\right)$, pancreas cancer $\left(P<0.01, l^{2}=88 \%\right)$ and liver cancer $\left(P=0.01, I^{2}=79 \%\right)$, while the heterogeneity of the remaining studies was moderate and low. We found that the association between the use of bisphosphonates and risk of all cancers was not statistically significant (pooled $\mathrm{RR}=0.96,95 \% \mathrm{Cl}$ : $0.90-1.02, P=0.18)$, with moderate heterogeneity between studies $\left(P<0.01, l^{2}=52 \%\right)$. Detailed meta-analyses for each type of cancers are in Supplementary Fig. S1.

Meta-regression and subgroup analysis

Random-effect meta-regression model and subgroup analysis were used to explore the primary heterogeneity in regard to population region, study design and sample size. The association between the use of bisphosphonates and risk of all cancers was weaker in the group of sample size $\geq 5000$ than in the group of sample size $<5000 \quad(P<0.01)$. We found no evidence that population region (Asia: $P=0.88$; Europe: $P=0.22$ ) and study design $(P=0.65)$ influenced the association between the use of bisphosphonates and risk of all cancers (Table 2).

The subgroup analysis was conducted based on different types of bisphosphonates for various types of cancers (Table 3). Nitrogen-containing bisphosphonates had a protective effect on breast cancer $\left(\mathrm{RR}=0.94,95 \% \mathrm{Cl}: 0.90-0.99, I^{2}=0 \%\right)$ and endometrial cancer ( $\mathrm{RR}=0.70,95 \% \mathrm{Cl}$ : $\left.0.54-0.92, \mathrm{I}^{2}=33 \%\right)$, but this effect was only observed in non-nitrogen-containing bisphosphonates on breast cancer $\left(\mathrm{RR}=0.88,95 \% \mathrm{Cl}\right.$ : $0.81-0.95, l^{2}=$ $39 \%)$. Notably, non-nitrogen-containing bisphosphonates tended to increase the risk of liver cancer $(\mathrm{RR}=2.14,95 \% \mathrm{Cl}$ : $1.23-3.72)$ and pancreas cancer ( $\mathrm{RR}=1.75,95 \% \mathrm{Cl}: 1.32-2.33)$.

Regarding the association between the duration of bisphosphonates and cancers, the use of bisphosphonates upto at least 1 year (RR $=0.78,95 \% \mathrm{Cl}$ : $\left.0.63-0.98, P^{2}=92 \%\right)$ had a greater protective effect on breast cancer than their use of less than 1 year $\left(\mathrm{RR}=0.90,95 \% \mathrm{Cl}\right.$ : 0.84-0.97, $\left.l^{2}=0 \%\right)$. Moreover, we observed a significant risk reduction for the use of bisphosphonates upto at least 1 year on prostate cancer $(R R=0.85,95 \%$ 


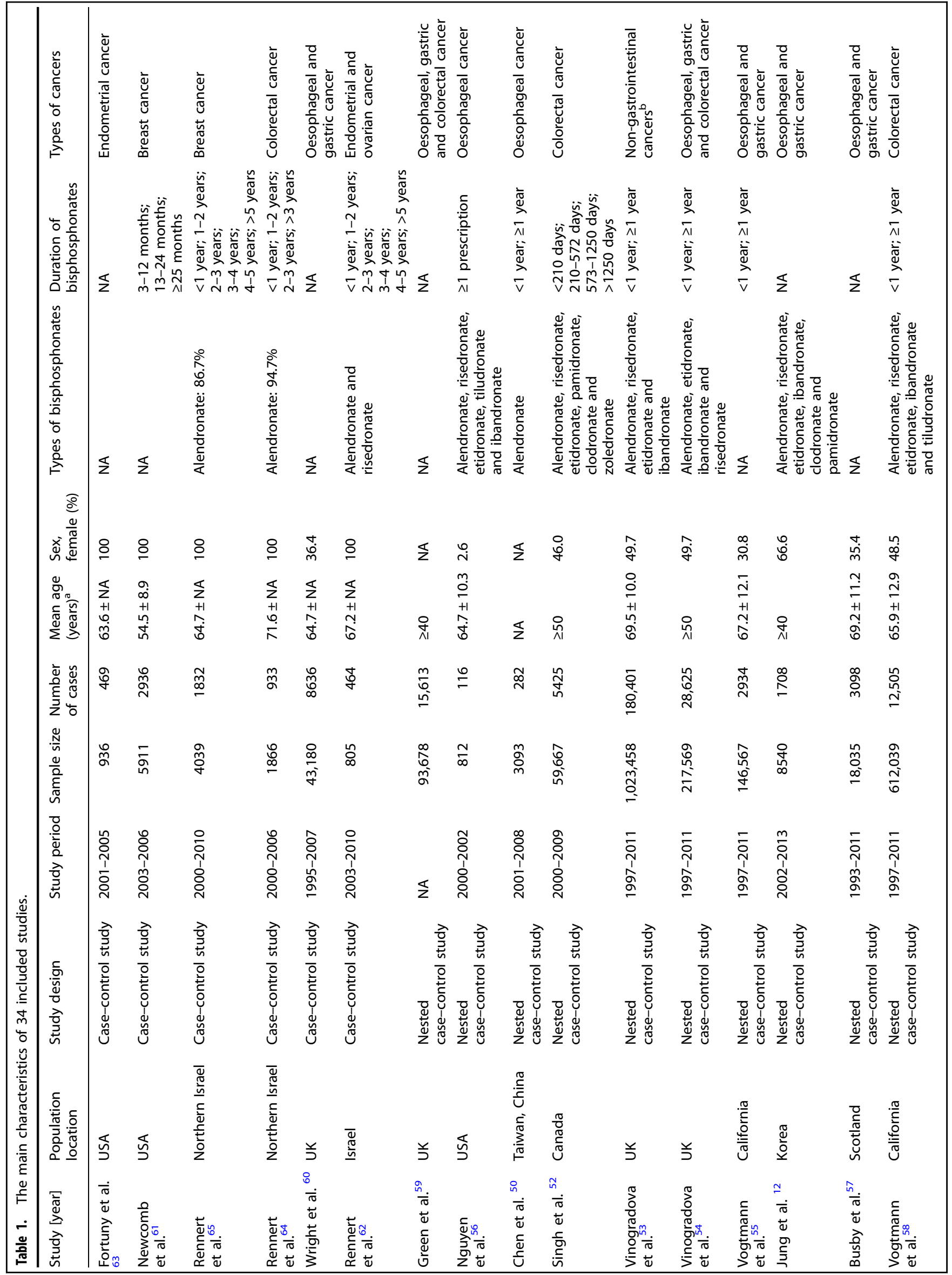




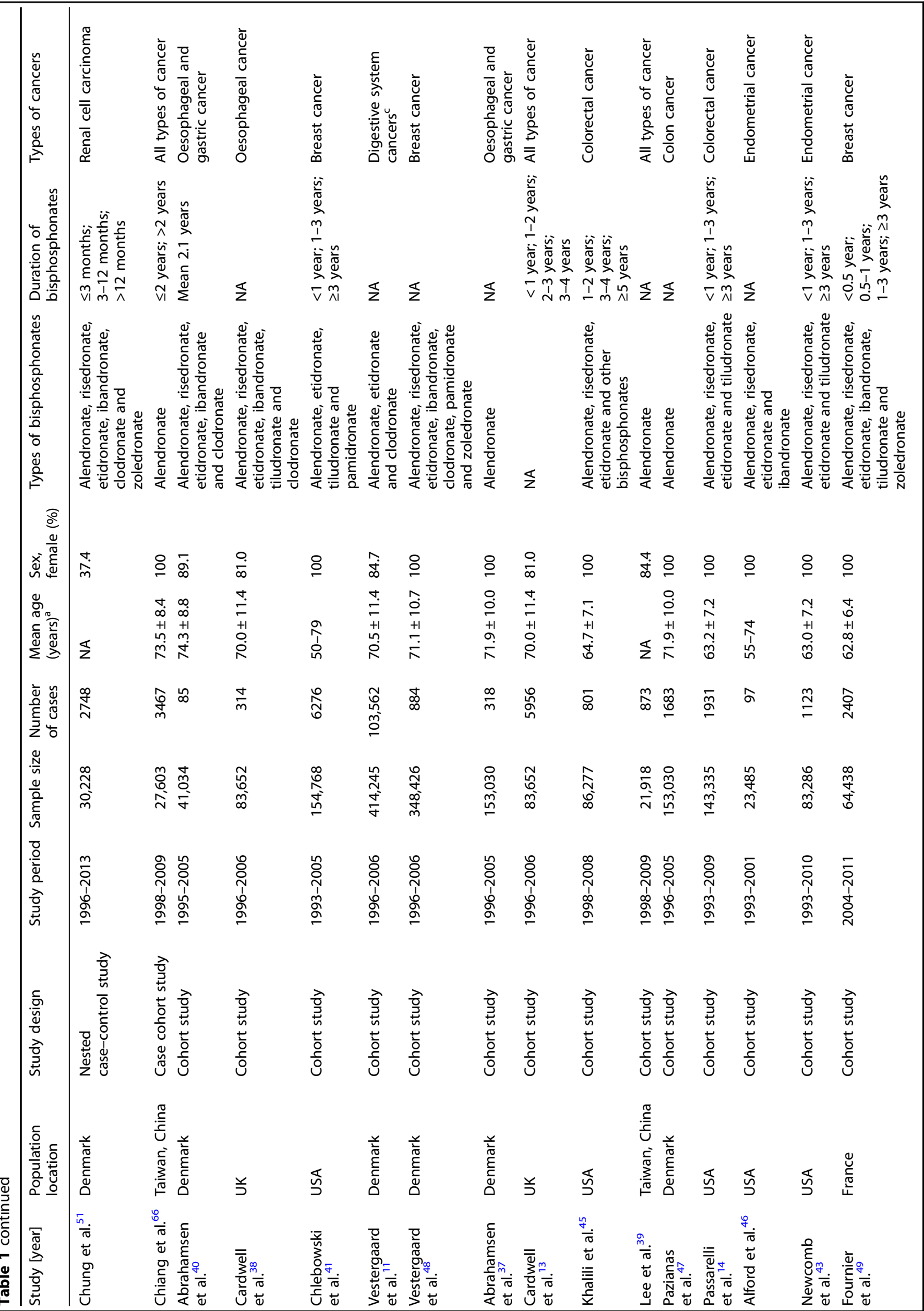


Cl: 0.76-0.95). However, there was no significant association on other types of cancers (Table 4).

Sensitivity analysis

We performed a sensitivity analysis by removing one study at each turn and calculating the pooled risk estimates with $95 \%$ Cls of the remaining studies. Two studies that were conducted by Abrahamsen et al. ${ }^{37,40}$ had an impact on the results in oesophageal cancer (pooled $\mathrm{RR}=1.13,95 \% \mathrm{Cl}$ : 0.98-1.31; removed Abrahamsen et al. 2012: $\mathrm{RR}=1.17,95 \% \mathrm{Cl}: 1.01-1.35$; removed Abrahamsen et al. 2009: $\mathrm{RR}=1.17,95 \% \mathrm{Cl}: 1.03-1.33)$. Besides, the association was not materially changed in this analysis in other types of cancers (Supplementary Figs. S2-S5).

Publication bias

The funnel plot of the association between the use of bisphosphonates and the risk of overall cancers as well as each type of cancer did not indicate substantial asymmetry (Fig. 3). For a specific type of cancers (including more than 10 articles), the Egger's liner regression test also implied no evidence of publication bias (all cancers: Egger's $P=0.83$; oesophageal cancer: Egger's $P=0.45$; colorectal cancer: Egger's $P=0.13$; gastric cancer: Egger's $P=0.92$; breast cancer: Egger's $P=0.26$ ) (Table 5). Potential publication bias was not found through the funnel plot and the Egger's liner regression test, so we did not carry out the trim-and-fill method.

\section{DISCUSSION}

Summary of the main results

The major findings of this meta-analysis are (1) the use of bisphosphonates might have a protective effect on colorectal, breast and endometrial cancer, but no significant association was observed with respect to all-cause cancer as well as other types of cancers. (2) Moreover, nitrogen-containing bisphosphonates could reduce the risk of breast cancer by $6 \%$ and endometrial cancer by $30 \%$; non-nitrogen-containing bisphosphonates could also reduce the risk of breast cancer by $12 \%$. However, non-nitrogencontaining bisphosphonates might be associated with an increased risk of liver and pancreas cancer. (3) The use of bisphosphonates upto at least 1 year had a greater protective effect on breast cancer than their use for less than 1 year, but such result was not found in other cancers.

Consistent and inconsistent with current studies

With regard to all-cause cancer, our results are largely consistent with previous meta-analyses in similar contexts, supporting that the association between bisphosphonates and the risk of allcause cancer is not statistically significant. ${ }^{26}$ The difference is that their study only included 13 cohort studies. Because this study had more sample size and the total number of cancer cases, we could examine more types of cancers and obtain higher statistical power. As we found that the sample size might be one of the sources of heterogeneity, we speculate that the use of bisphosphonates has a weak protective effect on allcause cancer, which needs more sample size to explore this association.

With regard to female cancers, our findings are consistent with previous studies that bisphosphonates could reduce the risk of breast $^{23,26,67,68}$ and endometrial cancer, ${ }^{22,24}$ but no significant link was observed in ovarian cancer. ${ }^{24}$ This might be due to the oestrogen receptor (ER) involved in the anticancer effect of bisphosphonates. ${ }^{69}$ Furthermore, the study by Chlebowski et al. ${ }^{41}$ showed that bisphosphonates reduced the risk of ER-positive breast cancer by $30 \%(\mathrm{HR}=0.70,95 \% \mathrm{Cl}: 0.52-0.95, P=0.02)$. However, the data on the association between bisphosphonates and ER-positive female cancers are poor, as we could not conduct subgroup analysis based on ER. Further studies are needed to 


\begin{tabular}{|c|c|c|c|c|c|c|}
\hline Types of cancers & $\begin{array}{l}\text { Number of } \\
\text { studies }\end{array}$ & RR $(95 \% \mathrm{Cl})$ & $\begin{array}{l}\% \\
\text { Weight }\end{array}$ & $\begin{array}{l}P \text { for } \\
\text { heterogeneity }\end{array}$ & $1^{2}$ & $\begin{array}{l}P \text { for } \\
\text { RR }\end{array}$ \\
\hline Oesophageal cancer & 14 & $1.13(0.98,1.31)$ & 7.80 & 0.01 & $52 \%$ & 0.10 \\
\hline Colorectal cancer & 12 & $0.89(0.81,0.98)$ & 10.28 & $<0.01$ & $80 \%$ & 0.02 \\
\hline Gastric cancer & 11 & $0.97(0.84,1.12)$ & 7.86 & 0.04 & $48 \%$ & 0.70 \\
\hline Breast cancer & 10 & $0.87(0.82,0.93)$ & 11.90 & 0.15 & $32 \%$ & $<0.01$ \\
\hline Endometrial cancer & 7 & $0.75(0.61,0.94)$ & 5.14 & 0.08 & $47 \%$ & 0.01 \\
\hline Lung cancer & 5 & $1.02(0.90,1.15)$ & 8.88 & 0.02 & $66 \%$ & 0.79 \\
\hline Ovarian cancer & 5 & $0.90(0.68,1.18)$ & 3.70 & 0.14 & $42 \%$ & 0.43 \\
\hline Bladder cancer & 4 & $0.97(0.80,1.18)$ & 5.83 & 0.20 & $36 \%$ & 0.74 \\
\hline Cervical cancer & 4 & $0.85(0.67,1.06)$ & 4.77 & 0.41 & $0 \%$ & 0.15 \\
\hline Pancreas cancer & 4 & $1.01(0.66,1.55)$ & 1.84 & $<0.01$ & $88 \%$ & 0.95 \\
\hline Liver cancer & 3 & $1.45(0.93,2.26)$ & 1.71 & 0.01 & $79 \%$ & 0.10 \\
\hline Prostate cancer & 3 & $0.92(0.66,1.27)$ & 2.85 & 0.06 & $65 \%$ & 0.59 \\
\hline Lymphoma or leukemia & 2 & $1.37(0.64,2.95)$ & 0.63 & 0.10 & $64 \%$ & 0.42 \\
\hline Melanoma & 2 & $0.97(0.83,1.15)$ & 7.02 & 0.29 & $10 \%$ & 0.76 \\
\hline Other sites or site unclear & a 2 & $0.87(0.76,0.98)$ & 8.65 & 0.56 & $0 \%$ & 0.03 \\
\hline Renal cell carcinoma & 2 & $1.08(0.95,1.22)$ & 8.75 & 0.75 & $0 \%$ & 0.24 \\
\hline Myeloma & 1 & $1.39(0.89,2.16)$ & 1.72 & & & 0.14 \\
\hline Oral cancer & 1 & $0.40(0.09,1.76)$ & 0.17 & & & 0.23 \\
\hline Small bowel cancer & 1 & $1.73(0.73,4.09)$ & 0.50 & & & 0.21 \\
\hline Overall $(\mathrm{I}$-squared $=51.8 \%$ & $3 \%, P=0.005)$ & $0.96(0.90,1.02)$ & 100.00 & & & \\
\hline \multicolumn{7}{|c|}{ NOTE: Weights are from random effects analysis } \\
\hline & $\begin{array}{ll}1 \\
0.09\end{array}$ & & & & & \\
\hline
\end{tabular}

Fig. 2 Forest plot of summary risk estimates in different types of cancers. The forest plot shows the RRs of different types of cancers comparing individuals using bisphosphonates to those without bisphosphonates. The types of cancers and the number of corresponding studies are shown in the figure. Each small rhombuses represents the RR for each type of cancer, with the location of the rhombuses representing both the direction and magnitude of the effect size and the horizontal line representing their $95 \% \mathrm{Cls}$. The square represents the weight of studies of each type of cancer. The hollow rhombus represents the pooled RRs. The maximally adjusted risk estimates with $95 \%$ Cls were pooled by using random-effect models to obtain a more conservative outcome. The heterogeneity among studies was evaluated by using the Cochrane's $Q$ statistic and the $I^{2}$ statistic, corresponding to the values of $P$ for heterogeneity and $I^{2}$ in the figure. $R R$ risk ratio; $C l$ confidence interval.

Table 2. Meta-regression and subgroup analyses with respect to all cancers.

\begin{tabular}{|c|c|c|c|c|}
\hline Subgroups & Number of studies & $\mathrm{RR}(95 \% \mathrm{Cl})$ & $P^{2}$ & $P^{*}$ \\
\hline Overall & 34 & $0.96(0.90-1.02)$ & $52 \%$ & \\
\hline \multicolumn{5}{|l|}{ Population region } \\
\hline America & 14 & $0.88(0.82-0.95)$ & $38 \%$ & Ref. \\
\hline Asia & 8 & $0.88(0.74-1.03)$ & $75 \%$ & 0.88 \\
\hline Europe & 12 & $0.96(0.89-1.03)$ & $88 \%$ & 0.22 \\
\hline \multicolumn{5}{|l|}{ Study design } \\
\hline Case-control & 18 & $0.95(0.89-1.01)$ & $70 \%$ & Ref. \\
\hline Cohort & 16 & $0.92(0.88-0.97)$ & $79 \%$ & 0.65 \\
\hline \multicolumn{5}{|l|}{ Sample size } \\
\hline$<5000$ & 6 & $0.71(0.62-0.83)$ & $0 \%$ & Ref. \\
\hline$\geq 5000$ & 28 & $0.94(0.90-0.99)$ & $81 \%$ & $<0.01$ \\
\hline
\end{tabular}

focus on the use of bisphosphonates and their protective effect on the different subtypes of female cancers to confirm these findings.

The effect of bisphosphonates on gastrointestinal cancers is controversial. The study by Oh et al. ${ }^{25}$ showed that there was no significant association between bisphosphonates and the risk of oesophageal cancer $(\mathrm{RR}=0.96,95 \% \mathrm{Cl}$ : $0.65-1.42)$, which was consistent with our results and other three meta-analyses. ${ }^{20,21,26}$
However, Andrici et al. ${ }^{70}$ found that bisphosphonates might increase the risk of oesophageal cancer (OR $=1.74,95 \% \mathrm{Cl}$ : 1.19-2.55). Similarly, the results regarding the association between bisphosphonates and the risk of gastric cancer are inconsistent. ${ }^{12,54,55}$ Clinical reports have found that bisphosphonates can cause gastrointestinal problems, such as erosive oesophagitis and gastric ulcers; ${ }^{71,72}$ these patients are more likely to receive the upper gastrointestinal endoscopy to accelerate the discovery of upper gastrointestinal cancer. In addition, because oesophageal adenocarcinoma of the distal oesophagus is very similar to the adenocarcinoma at the junction of the gastro-oesophagus, it is difficult to accurately distinguish them in clinical diagnosis. Original studies rarely report the results of subgroup analysis of the precise site of upper gastrointestinal cancer, as we are unable to perform pool analysis. We should focus on distinguishing the particular subtypes of oesophageal and gastric cancer when analysing the effects of bisphosphonates on gastric and oesophageal cancer in future studies. With respect to colorectal cancer, our study indicated that bisphosphonates could reduce the risk of colorectal cancer by $11 \%$, which was similar with other five metaanalyses, ${ }^{15-19}$ but Deng et al. ${ }^{26}$ and Oh et al. ${ }^{25}$ suggested that the association between bisphosphonates and the risk of colorectal cancer was not statistically significant. It is well known that bisphosphonates are commonly used for osteoporosis because they have lower bone mineral density (BMD). Previous studies have shown that BMD is associated with cancer, which means that if not adjusted, it might be a confounding factor that masks the protective effect of bisphosphonates. ${ }^{73,74}$ For other types of cancers, the results are basically similar to previous studies, and the number of related studies is few. ${ }^{26,75}$ 
Table 3. Subgroup analyses with respect to types of bisphosphonates.

\begin{tabular}{|c|c|c|c|c|c|c|c|c|}
\hline Subgroups ${ }^{\mathrm{a}}$ & \multicolumn{4}{|c|}{ Nitrogen-containing bisphosphonates } & \multicolumn{4}{|c|}{ Non-nitrogen-containing bisphosphonates } \\
\hline Gastric cancer & 6 & $0.91(0.75-1.10)$ & $30 \%$ & 0.21 & 2 & $1.07(0.53-2.17)$ & $87 \%$ & $<0.01$ \\
\hline Small-bowel cancer & 1 & $2.19(0.46-10.41)$ & NA & NA & 1 & $1.56(0.56-4.36)$ & NA & NA \\
\hline Bladder cancer & 2 & $1.18(0.60-2.29)$ & $47 \%$ & 0.17 & 1 & $1.41(0.79-2.53)$ & NA & NA \\
\hline Pancreas cancer & 2 & $1.11(0.77-1.62)$ & $7 \%$ & 0.30 & 1 & $1.75(1.32-2.33)$ & NA & NA \\
\hline Renal cell carcinoma & 2 & $1.15(0.77-1.72)$ & $0 \%$ & 0.99 & 1 & $1.18(0.94-1.49)$ & NA & NA \\
\hline Breast cancer & 6 & $0.94(0.90-0.99)$ & $0 \%$ & 0.68 & 2 & $0.88(0.81-0.95)$ & $39 \%$ & 0.20 \\
\hline Cervical cancer & 3 & $0.75(0.55-1.01)$ & $0 \%$ & 0.47 & NA & NA & NA & NA \\
\hline
\end{tabular}

Table 4. Subgroup analyses with respect to duration of bisphosphonates.

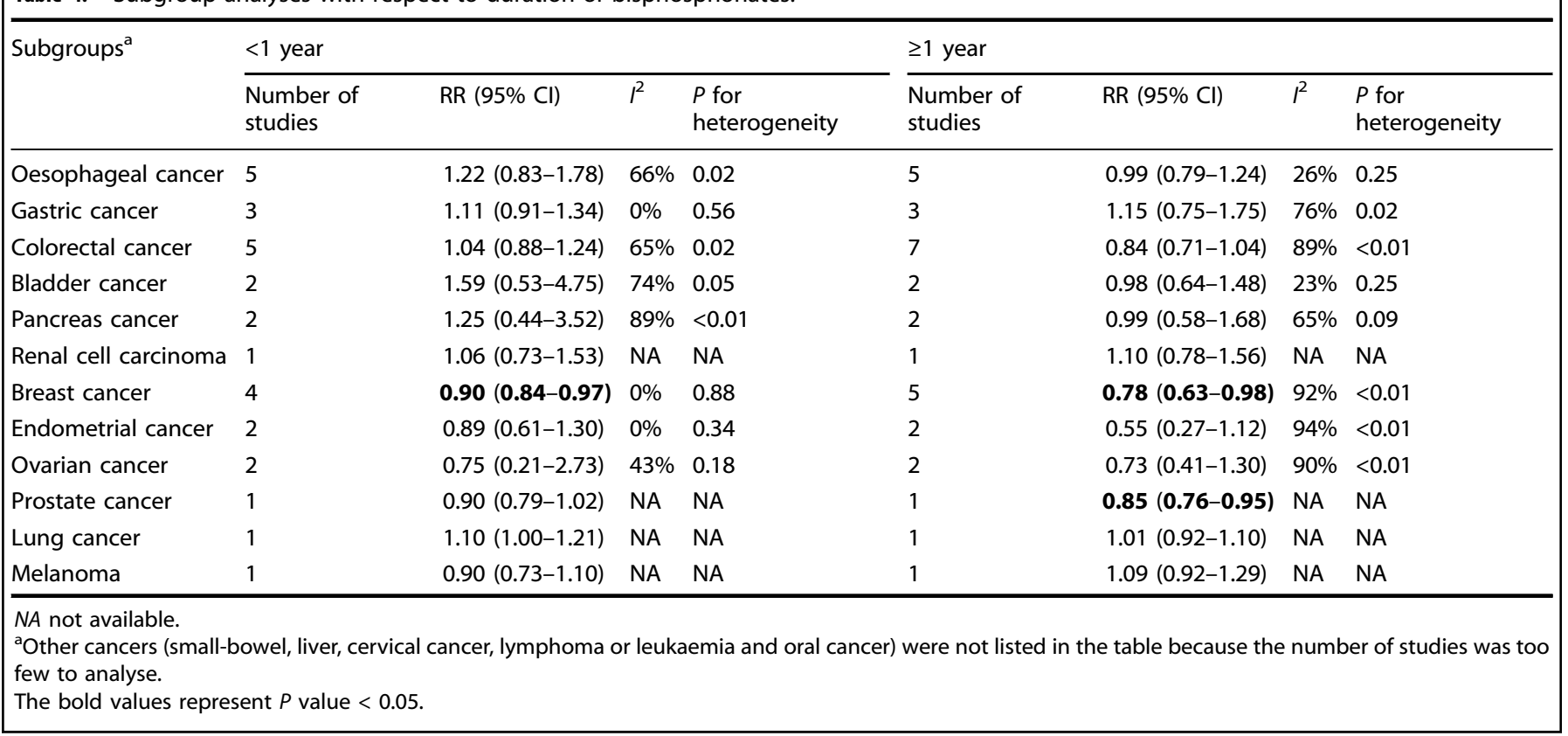

Types and duration of bisphosphonates and confounders Experimental studies have suggested that nitrogen-containing bisphosphonates have potential antitumour effects. They could reduce the viability of tumour cells by binding to the kinase domain of the human epidermal growth factor receptor $1 / 2$ (HER1/2), and resulting in an overall reduction in global downstream signalling that was driven by overexpression of the HER family, ${ }^{76,77}$ such as lung, ${ }^{78}$ breast $^{79}$ and colorectal cancer. ${ }^{80}$ We only observed that nitrogen-containing bisphosphonates could reduce $30 \%$ risk of endometrial cancer and $6 \%$ risk of breast cancer. However, there was no significant association between the use of nitrogen-containing bisphosphonates and risk of colorectal and lung cancer in our study. Simultaneously, we found that non- nitrogen-containing bisphosphonates might be associated with an increased risk of liver and pancreas cancer, which might be due to the greater toxicity on liver and pancreas. Clodronate (nonnitrogen-containing bisphosphonate) might cause evaluation of aminotransferase. ${ }^{81}$ Moreover, there were rare studies of liver disease developing in patients who use non-nitrogen-containing bisphosphonate. ${ }^{82,83}$ In addition, from the limited information, we could not find any possible mechanism to explain the association between non-nitrogen-containing bisphosphonates and the risk of pancreas cancer, but we should pay attention to the safety of using this drug. In the future, it might be necessary to further explore the pharmacological mechanisms of non-nitrogencontaining bisphosphonates. 


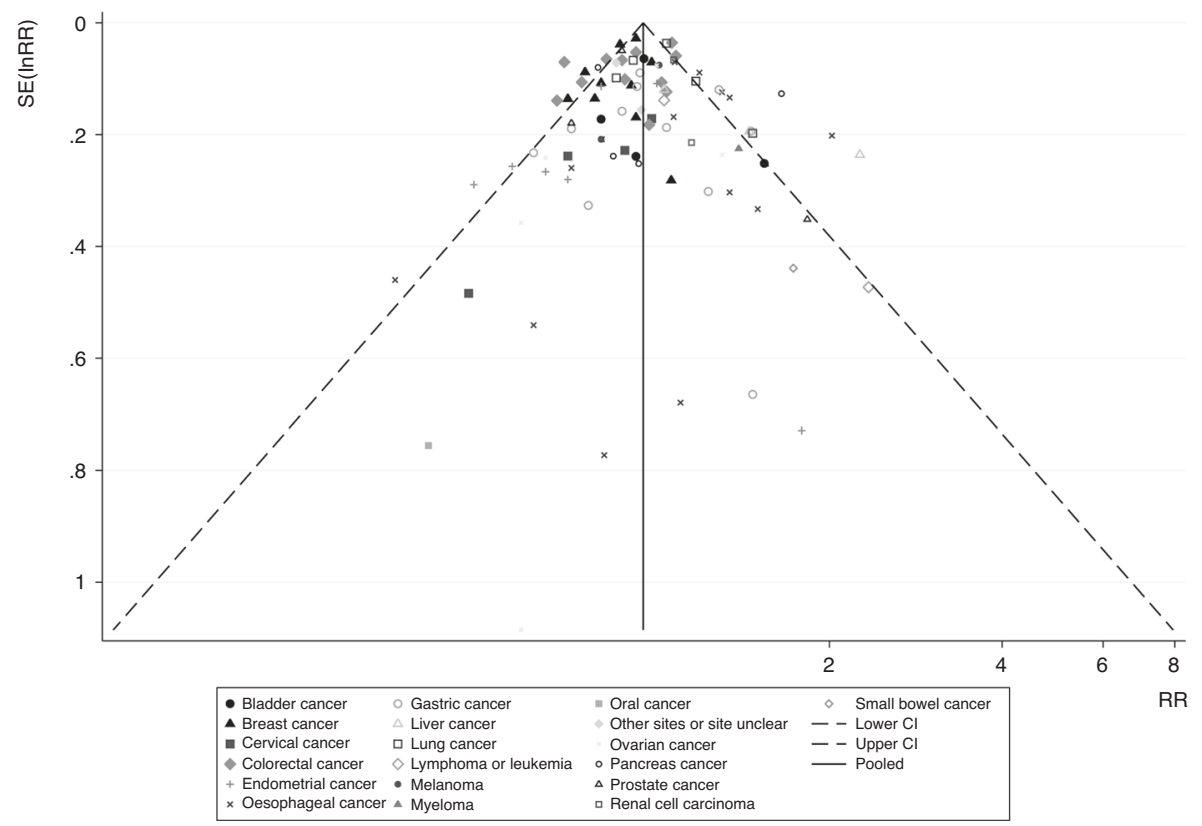

Fig. 3 Funnel plot of the meta-analysis of the association between bisphosphonates and risk of all cancers. The abscissa is the effect size (RR), and the ordinate is the standard error of the effect size (SE (InRR)). Small symbols of different shapes represent the studies involved in different cancers. The vertical line in the middle represents the combined RR value, and the two oblique dashed lines represent the $95 \%$ confidence intervals of the funnel graph. The funnel plot of the association between the use of bisphosphonates and the risk of overall cancers as well as each type of cancer did not indicate substantial asymmetry.

Table 5. The bias examination of the association between bisphosphonates and risk of cancers.

\begin{tabular}{lll|}
\hline Types of cancers & Number of studies & $\begin{array}{l}P \text { value for Egger's liner } \\
\text { regression test }\end{array}$ \\
\hline All cancers & 34 & 0.83 \\
Oesophageal cancer & 14 & 0.45 \\
Colorectal cancer & 12 & 0.13 \\
Gastric cancer & 11 & 0.92 \\
Breast cancer & 10 & 0.26 \\
\hline
\end{tabular}

Notably, we did not find that the duration of bisphosphonates had an effect on specific cancers, except breast cancer. For breast cancer, our results were consistent with a meta-analysis by Liu et al., ${ }^{68}$ which showed that using bisphosphonates upto at least 1 year $(\mathrm{RR}=0.75$, 95\% Cl: 0.66-0.84) seemed to be greater protective on breast cancer than using them for less than 1 year ( $\mathrm{RR}=0.90,95 \% \mathrm{Cl}$ : 0.84-0.97). However, $\mathrm{Ou}$ et al. $^{23}$ suggested that bisphosphonate was not associated with risk of breast cancer when the usage time was less than 1 year ( $R R=0.93,95 \%: 0.86-1.00$ ), but a significant $26 \%$ reduction was found upto at least 1 year $(\mathrm{RR}=0.74,95 \% \mathrm{Cl}$ : $0.66-0.83$ ), which was consistent with the study by Newcomb et al. ${ }^{61}$ Patients with the long-term use of bisphosphonates might have a healthier lifestyle and higher adherence to the drugs, so the benefits observed in the analysis might be overestimated. ${ }^{84}$ Thus, further studies are needed to consider this potential bias and find the best duration and dose of bisphosphonates.

In this study, the evidence we have on the use of bisphosphonates and risk of cancers is based mainly on observational studies. Many studies are not able to adequately control confounding factors related to cancers. Wright et al. ${ }^{60}$ demonstrated a small but significantly increased risk of oesophageal cancer in women, not in men. Generally, women prescribe bisphosphonates for prevention and treatment of osteoporosis, while men are more likely to prescribe bisphosphonates for iatrogenic osteoporosis. ${ }^{85,86}$ Hence, most of the participants in included studies were women, and the number of men was much smaller. To date, there is still a lack of studies on the association between bisphosphonates and risk of cancers in people of different genders. Secondly, some studies have reported that supplemental calcium and vitamin $\mathrm{D}$ might have a protective effect on colorectal cancer, which are usually prescribed with bisphosphonates. ${ }^{87,88}$ Some included studies did not control for calcium and vitamin $\mathrm{D}$ when analysing the association between bisphosphonates and the risk of colorectal cancer. ${ }^{52,54,58}$ In addition, only a few studies adjust the use of statins, hormone replacement therapy (HRT) and family history of cancers, which are also related to cancers. ${ }^{44-46,49}$

Strengths and limitations

This study has several strengths. First, there are many articles and a large number of participants included in this study, which increases the statistical power of the analysis. Furthermore, we explore the sources of heterogeneity by meta-regression and subgroup analysis. Finally, this systematic review and meta-analysis has an update to the summary articles in this field. However, several limitations of this study must be mentioned. Firstly, our study includes observational studies (cohort studies, case-control studies, nested case-control studies and case cohort studies) that might differ in the design of researches and lack individual information. In addition, evidence from observational studies is weaker than that from randomised controlled trials. Secondly, the meta-analysis of observational studies is susceptible to confounding factors that exist in original studies because most of the included studies use large and anonymous databases. ${ }^{89}$ Although all included studies attempt to adjust confounding factors, there are still potential confounders that are not considered, which might affect our results. Thirdly, we are unable to perform subgroup analysis of precise sites of oesophageal and gastric cancer, because the original studies rarely report the results in this aspect. Finally, although we have explored several sources of heterogeneity with meta-regression model and subgroup analysis, it still cannot fully explain the heterogeneity in the studies. 


\section{CONCLUSIONS}

In conclusion, the results of this meta-analysis suggest that the use of bisphosphonates is associated with a decreased risk of colorectal, breast and endometrial cancer, but not significantly associated with the risk of oesophageal and other types of cancers. Furthermore, we find that nitrogen-containing bisphosphonates appear to have more antitumour effects, but nonnitrogen- containing bisphosphonates might be associated with an increased risk of liver and pancreas cancer. In addition, the use of bisphosphonates for at least 1 year has a greater protective effect on breast cancer than their use for less than 1 year. We recommend that further large prospective cohort studies are needed to explore the causal association between bisphosphonates and cancers, and more studies of potential mechanism are required. After a careful benefit-and-risk assessment, whether nitrogen-containing bisphosphonates are expected to be used in populations at a high risk for the malignancies needs further discussion.

\section{ACKNOWLEDGEMENTS}

Not applicable.

\section{AUTHOR CONTRIBUTIONS}

Study concept and design: Y.P.L., C.X.J. and Y.Y.L.; data collection and collation: Y.Y.L, S.J.L. and S.C.; statistical analysis: Y.Y.L., L.J.G. and Y.X.Z; writing-original draft: Y.Y.L.; writing-review and editing: all authors; study supervision: Y.P.L., C.X.J., L.J.G. and Y.X.Z. All authors contributed to data analysis, drafting or revision of this paper, and approved the final version. The corresponding authors prove that all listed authors meet the authorship criteria, and that no other eligible authors have been omitted.

\section{ADDITIONAL INFORMATION}

Ethics approval and consent to participate All analyses were based on previously published studies; thus, no ethical approval and patient consent are required.

Consent to publish Not applicable.

Data availability The datasets used and analysed during the current study are available from the corresponding author on reasonable request.

Competing interests The authors declare no competing interests.

Funding information This research did not receive any specific grant from funding agencies in the public, commercial or not-for-profit sectors.

Supplementary information is available for this paper at https://doi.org/10.1038/ s41416-020-01043-9.

Note This work is published under the standard license to publish agreement. After 12 months the work will become freely available and the license terms will switch to a Creative Commons Attribution 4.0 International (CC BY 4.0).

Publisher's note Springer Nature remains neutral with regard to jurisdictional claims in published maps and institutional affiliations.

\section{REFERENCES}

1. Feng, R. M., Zong, Y. N., Cao, S. M. \& Xu, R. H. Current cancer situation in China: good or bad news from the 2018 Global Cancer Statistics? Cancer Commun. (Lond.) 39, 22 (2019).

2. Fitzmaurice, C., Abate, D., Abbasi, N., Abbastabar, H., Abd-Allah, F., Abdel-Rahman, O. et al. Global, regional, and national cancer incidence, mortality, years of life lost, years lived with disability, and disability-adjusted life-years for 29 cancer groups, 1990 to 2017: A Systematic Analysis for the Global Burden of Disease Study. JAMA Oncol. 5, 1749-1768 (2019).

3. Bray, F., Ferlay, J., Soerjomataram, l., Siegel, R. L., Torre, L. A. \& Jemal, A. Global cancer statistics 2018: GLOBOCAN estimates of incidence and mortality worldwide for 36 cancers in 185 countries. CA Cancer J. Clin. 68, 394-424 (2018).
4. van der Pluijm, G., Vloedgraven, H., van Beek, E., van der Wee-Pals, L., Lowik, C. \& Papapoulos, S. Bisphosphonates inhibit the adhesion of breast cancer cells to bone matrices in vitro. J. Clin. Invest. 98, 698-705 (1996).

5. Sewing, L., Steinberg, F., Schmidt, H. \& Göke, R. The bisphosphonate zoledronic acid inhibits the growth of HCT-116 colon carcinoma cells and induces tumor cell apoptosis. Apoptosis 13, 782-789 (2008).

6. Tsubaki, M., Itoh, T., Satou, T., Imano, M., Komai, M., Ogawa, N. et al. Nitrogencontaining bisphosphonates induce apoptosis of hematopoietic tumor cells via inhibition of Ras signaling pathways and Bim-mediated activation of the intrinsic apoptotic pathway. Biochem Pharm. 85, 163-172 (2013).

7. Tang, X. D., Zhang, Q. Z., Shi, S. H., Yen, Y., Li, X. Y., Zhang, Y. F. et al. Bisphosphonates suppress insulin-like growth factor 1-induced angiogenesis via the HIF-1 alpha/VEGF signaling pathways in human breast cancer cells. Int J. Cancer 126, 90-103 (2010).

8. Reusser, N. M., Dalton, H. J., Pradeep, S., Gonzalez-Villasana, V., Jennings, N. B., Vasquez, H. G. et al. Clodronate inhibits tumor angiogenesis in mouse models of ovarian cancer. Cancer Biol. Ther. 15, 1061-1067 (2014).

9. Guise, T. A. Antitumor effects of bisphosphonates: promising preclinical evidence. Cancer Treat. Rev. 34, S19-S24 (2008).

10. Wysowski, D. K. Reports of esophageal cancer with oral bisphosphonate use. $N$. Engl. J. Med. 360, 89-90 (2009).

11. Vestergaard, P. Occurrence of gastrointestinal cancer in users of bisphosphonates and other antiresorptive drugs against osteoporosis. Calcif. Tissue Int. 89, 434-441 (2011).

12. Jung, S. Y., Sohn, H. S., Park, E. J., Suh, H. S., Park, J. W. \& Kwon, J. W. Oral bisphosphonates and upper gastrointestinal cancer risks in Asians with osteoporosis: a nested case-control study using National Retrospective Cohort Sample Data from Korea. PLOS ONE 11, e0150531 (2016).

13. Cardwell, C. R., Abnet, C. C., Veal, P., Hughes, C. M., Cantwell, M. M. \& Murray, L. J. Exposure to oral bisphosphonates and risk of cancer. Int J. Cancer 131, E717-E725 (2012).

14. Passarelli, M. N., Newcomb, P. A., LaCroix, A. Z., Lane, D. S., Ho, G. Y. \& Chlebowski, R. T. Oral bisphosphonate use and colorectal cancer incidence in the Women's Health Initiative. J. Bone Min. Res. 28, 2043-2048 (2013).

15. Bonovas, S., Nikolopoulos, G. \& Bagos, P. Bisphosphonate use and risk of colorectal cancer: a systematic review and meta-analysis. Br. J. Clin. Pharm. 76, 329-337 (2013).

16. Ma, J., Gao, S., Ni, X., Chen, F., Liu, X., Xie, H. et al. Exposure to bisphosphonates and risk of colorectal cancer. Br. J. Clin. Pharm. 76, 320-328 (2013).

17. Singh, S., Singh, A. G., Murad, M. H. \& Limburg, P. J. Bisphosphonates are associated with reduced risk of colorectal cancer: a systematic review and metaanalysis. Clin. Gastroenterol. Hepatol. 11, 232-239.e231 (2013).

18. Thosani, N., Thosani, S. N., Kumar, S., Nugent, Z., Jimenez, C., Singh, H. et al. Reduced risk of colorectal cancer with use of oral bisphosphonates: a systematic review and meta-analysis. J. Clin. Oncol. 31, 623-630 (2013).

19. Yang, G., Hu, H., Zeng, R. \& Huang, J. Oral bisphosphonates and the risk of colorectal cancer: a meta-analysis. J. Clin. Gastroenterol. 47, 741-748 (2013).

20. Sun, K., Liu, J. M., Sun, H. X., Lu, N. \& Ning, G. Bisphosphonate treatment and risk of esophageal cancer: a meta-analysis of observational studies. Osteoporos. Int. 24, 279-286 (2013).

21. Wright, E., Schofield, P. T. \& Molokhia, M. Bisphosphonates and evidence for association with esophageal and gastric cancer: a systematic review and metaanalysis. BMJ Open 5, e007133 (2015).

22. Ou, Y. J., Chiu, H. F., Wong, Y. H. \& Yang, Y. H. Bisphosphonate use and the risk of endometrial cancer: a meta-analysis of observational studies. Pharmacoepidemiol. Drug Saf. 25, 1107-1115 (2016).

23. Ou, Y. J., Chiu, H. F., Wong, Y. H., Yang, C. C. \& Yang, Y. H. Bisphosphonate use and the risk of breast cancer: a meta-analysis of observational studies. Pharmacoepidemiol. Drug Saf. 26, 1286-1295 (2017).

24. Zhang, X. S., Zhang, Y. M., Li, B., Fan, B., Zhao, Y. \& Yang, S. J. Risk reduction of endometrial and ovarian cancer after bisphosphonates use: a meta-analysis. Gynecol. Oncol. 150, 509-514 (2018).

25. Oh, Y. H., Yoon, C. \& Park, S. M. Bisphosphonate use and gastrointestinal tract cancer risk: meta-analysis of observational studies. World J. Gastroenterol. 18, 5779-5788 (2012).

26. Deng, Y., Zhang, Z., Jia, X., Cheng, W., Zhou, X., Liu, Y. et al. Oral bisphosphonates and incidence of cancers in patients with osteoporosis: a systematic review and meta-analysis. Arch. Osteoporos. 14, 1 (2019).

27. Liberman, U. A., Weiss, S. R., Broll, J., Minne, H. W., Quan, H., Bell, N. H. et al. Effect of oral alendronate on bone mineral density and the incidence of fractures in postmenopausal osteoporosis. the Alendronate Phase III Osteoporosis Treatment Study Group. N. Engl. J. Med. 333, 1437-1443 (1995).

28. Watts, N. B., Harris, S. T., Genant, H. K., Wasnich, R. D., Miller, P. D., Jackson, R. D. et al. Intermittent cyclical etidronate treatment of postmenopausal osteoporosis. N. Engl. J. Med. 323, 73-79 (1990). 
29. Moher, D., Liberati, A., Tetzlaff, J. \& Altman, D. G. Preferred reporting items for systematic reviews and meta-analyses: the PRISMA statement. BMJ 339, b2535 (2009).

30. Wells, G., Shea, B., O'Connell, D., Peterson, J., Welch, V., Losos, M. et al. The Newcastle-Ottawa Scale (NOS) for assessing the quality of nonrandomised studies in meta-analyses. http://www.ohri.ca/programs/clinical_epidemiology/ oxford.asp (2014).

31. McNutt, L. A., Wu, C., Xue, X. \& Hafner, J. P. Estimating the relative risk in cohort studies and clinical trials of common outcomes. Am. J. Epidemiol. 157, 940-943 (2003).

32. Higgins, J. P. \& Thompson, S. G. Quantifying heterogeneity in a meta-analysis. Stat. Med. 21, 1539-1558 (2002).

33. Russell, R. G. Bisphosphonates: the first 40 years. Bone 49, 2-19 (2011).

34. Sterne, J. A. \& Egger, M. Funnel plots for detecting bias in meta-analysis: guidelines on choice of axis. J. Clin. Epidemiol. 54, 1046-1055 (2001).

35. Egger, M., Davey Smith, G., Schneider, M. \& Minder, C. Bias in meta-analysis detected by a simple, graphical test. BMJ 315, 629-634 (1997).

36. Duval, S. \& Tweedie, R. Trim and fill: a simple funnel-plot-based method of testing and adjusting for publication bias in meta-analysis. Biometrics 56, 455-463 (2000).

37. Abrahamsen, B., Pazianas, M., Eiken, P., Russell, R. G. \& Eastell, R. Esophageal and gastric cancer incidence and mortality in alendronate users. J. Bone Min. Res. 27, 679-686 (2012).

38. Cardwell, C. R., Abnet, C. C., Cantwell, M. M. \& Murray, L. J. Exposure to oral bisphosphonates and risk of esophageal cancer. JAMA 304, 657-663 (2010).

39. Lee, W. Y., Sun, L. M., Lin, M. C., Liang, J. A., Chang, S. N., Sung, F. C. et al. A higher dosage of oral alendronate will increase the subsequent cancer risk of osteoporosis patients in Taiwan: a population-based cohort study. PLOS ONE 7, e53032 (2012).

40. Abrahamsen, B., Eiken, P. \& Eastell, R. More on reports of esophageal cancer with oral bisphosphonate use. N. Engl. J. Med. 360, 1789 (2009).

41. Chlebowski, R. T., Chen, Z., Cauley, J. A., Anderson, G., Rodabough, R. J., McTiernan, A. et al. Oral bisphosphonate use and breast cancer incidence in postmenopausal women. J. Clin. Oncol. 28, 3582-3590 (2010).

42. Tao, M. H., Chen, S., Freudenheim, J. L., Cauley, J. A., Johnson, K. C., Mai, X. et al. Oral bisphosphonate use and lung cancer incidence among postmenopausal women. Ann. Oncol. 29, 1476-1485 (2018).

43. Newcomb, P. A., Passarelli, M. N., Phipps, A. I., Anderson, G. L., Wactawski-Wende, J., Ho, G. Y. et al. Oral bisphosphonate use and risk of postmenopausal endometrial cancer. J. Clin. Oncol. 33, 1186-1190 (2015).

44. Bae, Y. S., Chang, J. \& Park, S. M. Oral bisphosphonate use and the risk of female breast, ovarian, and cervical cancer: a nationwide population-based cohort study. Arch. Osteoporos. 14, 41 (2019).

45. Khalili, H., Huang, E. S., Ogino, S., Fuchs, C. S. \& Chan, A. T. A prospective study of bisphosphonate use and risk of colorectal cancer. J. Clin. Oncol. 30, 3229-3233 (2012).

46. Alford, S. H., Rattan, R., Buekers, T. E. \& Munkarah, A. R. Protective effect of bisphosphonates on endometrial cancer incidence in data from the prostate, lung, colorectal and ovarian (PLCO) cancer screening trial. Cancer 121, 441-447 (2015).

47. Pazianas, M., Abrahamsen, B., Eiken, P. A., Eastell, R. \& Russell, R. G. Reduced colon cancer incidence and mortality in postmenopausal women treated with an oral bisphosphonate-Danish National Register Based Cohort Study. Osteoporos. Int. 23, 2693-2701 (2012).

48. Vestergaard, P., Fischer, L., Mele, M., Mosekilde, L. \& Christiansen, P. Use of bisphosphonates and risk of breast cancer. Calcif. Tissue Int. 88, 255-262 (2011).

49. Fournier, A., Mesrine, S., Gelot, A., Fagherazzi, G., Baglietto, L., Clavel-Chapelon, F. et al. Use of bisphosphonates and risk of breast cancer in a French cohort of postmenopausal women. J. Clin. Oncol. 35, 3230-3239 (2017).

50. Chen, Y. M., Chen, D. Y., Chen, L. K., Tsai, Y. W., Chang, L. C., Huang, W. F. et al. Alendronate and risk of esophageal cancer: a nationwide population-based study in Taiwan. J. Am. Geriatr. Soc. 59, 2379-2381 (2011).

51. Chung, B. I., Hellfritzsch, M., Ulrichsen, S. P., Sørensen, H. T. \& Ehrenstein, V. Bisphosphonate use and risk of renal cell carcinoma: a population-based casecontrol study. Basic Clin. Pharm. Toxicol. 124, 642-646 (2018).

52. Singh, H., Nugent, Z., Demers, A., Mahmud, S. \& Bernstein, C. Exposure to bisphosphonates and risk of colorectal cancer: a population-based nested casecontrol study. Cancer 118, 1236-1243 (2012).

53. Vinogradova, Y., Coupland, C. \& Hippisley-Cox, J. Exposure to bisphosphonates and risk of common non-gastrointestinal cancers: series of nested case-control studies using two primary-care databases. Br. J. Cancer 109, 795-806 (2013).

54. Vinogradova, Y., Coupland, C. \& Hippisley-Cox, J. Exposure to bisphosphonates and risk of gastrointestinal cancers: series of nested case-control studies with QResearch and CPRD data. BMJ 346, f114 (2013).
55. Vogtmann, E., Corley, D. A., Almers, L. M., Cardwell, C. R., Murray, L. J. \& Abnet, C. C. Oral bisphosphonate exposure and the risk of upper gastrointestinal cancers. PLOS ONE 10, e0140180 (2015).

56. Nguyen, D. M., Schwartz, J., Richardson, P. \& El-Serag, H. B. Oral bisphosphonate prescriptions and the risk of esophageal adenocarcinoma in patients with Barrett's esophagus. Dig. Dis. Sci. 55, 3404-3407 (2010).

57. Busby, J., Murchie, P., Murray, L., Iversen, L., Lee, A. J., Spence, A. et al. The effect of medications which cause inflammation of the gastro-oesophageal tract on cancer risk: a nested case-control study of routine Scottish data. Int J. Cancer 140, 1828-1835 (2017).

58. Vogtmann, E., Corley, D. A., Almers, L. M., Cardwell, C. R., Murray, L. J. \& Abnet, C. C. Oral bisphosphonates and colorectal cancer. Sci. Rep. 7, 44177 (2017).

59. Green, J., Czanner, G., Reeves, G., Watson, J., Wise, L. \& Beral, V. Oral bisphosphonates and risk of cancer of oesophagus, stomach, and colorectum: casecontrol analysis within a UK primary care cohort. BMJ 341, c4444 (2010).

60. Wright, E., Schofield, P. T., Seed, P. \& Molokhia, M. Bisphosphonates and risk of upper gastrointestinal cancer-a case control study using the General Practice Research Database (GPRD). PLoS ONE 7, e47616 (2012).

61. Newcomb, P. A., Trentham-Dietz, A. \& Hampton, J. M. Bisphosphonates for osteoporosis treatment are associated with reduced breast cancer risk. Br. J. Cancer 102, 799-802 (2010).

62. Rennert, G., Rennert, H. S., Pinchev, M. \& Lavie, O. The effect of bisphosphonates on the risk of endometrial and ovarian malignancies. Gynecol. Oncol. 133, 309-313 (2014).

63. Fortuny, J., Sima, C., Bayuga, S., Wilcox, H., Pulick, K., Faulkner, S. et al. Risk of endometrial cancer in relation to medical conditions and medication use. Cancer Epidemiol. Biomark. Prev. 18, 1448-1456 (2009).

64. Rennert, G., Pinchev, M., Rennert, H. S. \& Gruber, S. B. Use of bisphosphonates and reduced risk of colorectal cancer. J. Clin. Oncol. 29, 1146-1150 (2011).

65. Rennert, G., Pinchev, M. \& Rennert, H. S. Use of bisphosphonates and risk of postmenopausal breast cancer. J. Clin. Oncol. 28, 3577-3581 (2010).

66. Chiang, C. H., Huang, C. C., Chan, W. L., Huang, P. H., Chen, T. J., Chung, C. M. et al. Oral alendronate use and risk of cancer in postmenopausal women with osteoporosis: A nationwide study. J. Bone Min. Res. 27, 1951-1958 (2012).

67. Liu, Y., Zhao, S., Chen, W., Hu, F., Zhu, L., Zhang, Q. et al. Bisphosphonate use and the risk of breast cancer: a meta-analysis of published literature. Clin. Breast Cancer 12, 276-281 (2012).

68. Liu, Y., Zhang, X., Sun, H., Zhao, S., Zhang, Y., Li, D. et al. Bisphosphonates and primary breast cancer risk: an updated systematic review and meta-analysis involving 963,995 women. Clin. Epidemiol. 11, 593-603 (2019).

69. Journe, F., Chaboteaux, C., Dumon, J. C., Leclercq, G., Laurent, G. \& Body, J. J. Steroid-free medium discloses oestrogenic effects of the bisphosphonate clodronate on breast cancer cells. Br. J. Cancer 91, 1703-1710 (2004).

70. Andrici, J., Tio, M. \& Eslick, G. D. Meta-analysis: oral bisphosphonates and the risk of oesophageal cancer. Aliment Pharm. Ther. 36, 708-716 (2012).

71. Abraham, S. C., Cruz-Correa, M., Lee, L. A., Yardley, J. H. \& Wu, T. T. Alendronateassociated esophageal injury: pathologic and endoscopic features. Mod. Pathol. 12, 1152-1157 (1999).

72. Graham, D. Y. \& Malaty, H. M. Alendronate and naproxen are synergistic for development of gastric ulcers. Arch. Intern. Med. 161, 107-110 (2001).

73. Lee, H. F., Wu, C. E., Lin, Y. S., Hwang, J. S., Wu, C. H. \& Chu, P. H. Low bone mineral density may be associated with long-term risk of cancer in the middle-aged population: A retrospective observational study from a single center. J. Formos. Med Assoc. 117, 339-345 (2018).

74. Nock, N. L., Patrick-Melin, A., Cook, M., Thompson, C., Kirwan, J. P. \& Li, L. Higher bone mineral density is associated with a decreased risk of colorectal adenomas. Int. J. Cancer 129, 956-964 (2011).

75. Chen, L. X., Ning, G. Z., Zhou, Z. R., Li, Y. L., Zhang, D., Wu, Q. L. et al. The carcinogenicity of alendronate in patients with osteoporosis: evidence from cohort studies. PLOS ONE 10, e0123080 (2015).

76. Stachnik, A., Yuen, T., Iqbal, J., Sgobba, M., Gupta, Y., Lu, P. et al. Repurposing of bisphosphonates for the prevention and therapy of nonsmall cell lung and breast cancer. Proc. Natl Acad. Sci. USA 111, 17995-18000 (2014).

77. Yuen, T., Stachnik, A., Iqbal, J., Sgobba, M., Gupta, Y., Lu, P. et al. Bisphosphonates inactivate human EGFRs to exert antitumor actions. Proc. Natl Acad. Sci. USA 111, 17989-17994 (2014).

78. Dacic, S. EGFR assays in lung cancer. Adv. Anat. Pathol. 15, 241-247 (2008).

79. Gonzalez-Conchas, G. A., Rodriguez-Romo, L., Hernandez-Barajas, D., GonzalezGuerrero, J. F., Rodriguez-Fernandez, I. A., Verdines-Perez, A. et al. Epidermal growth factor receptor overexpression and outcomes in early breast cancer: A systematic review and a meta-analysis. Cancer Treat. Rev. 62, 1-8 (2018).

80. Krasinskas, A. M. EGFR Signaling in Colorectal Carcinoma. Pathol. Res Int. 2011, 932932 (2011).

81. Laitinen, K. \& Taube, T. Clodronate as a cause of aminotransferase elevation. Osteoporos. Int. 10, 120-122 (1999). 
82. Välimäki, M. J., Laitinen, K., Patronen, A., Puolijoki, H., Seppänen, J., Pylkkänen, L. et al. Prevention of bone loss by clodronate in early postmenopausal women with vertebral osteopenia: a dose-finding study. Osteoporos. Int. 13, 937-947 (2002).

83. Lewiecki, E. M. Safety of long-term bisphosphonate therapy for the management of osteoporosis. Drugs 71, 791-814 (2011).

84. Eiken, P. \& Vestergaard, P. Oral bisphosphonates and colon cancer: an update. Ther. Adv. Musculoskelet. Dis. 7, 160-168 (2015).

85. Minisola, S., Cipriani, C., Scillitani, A. \& Pepe, J. More on the use of bisphosphonates in the prevention and treatment of osteoporosis. BMJ 351, h5868 (2015).
86. Brown, S. A. \& Guise, T. A. Drug insight: the use of bisphosphonates for the prevention and treatment of osteoporosis in men. Nat. Clin. Pract. Urol. 4, 310-320 (2007).

87. Zhang, X. \& Giovannucci, E. Calcium, vitamin D and colorectal cancer chemoprevention. Best. Pr. Res Clin. Gastroenterol. 25, 485-494 (2011).

88. Heine-Bröring, R. C., Winkels, R. M., Renkema, J. M. S., Kragt, L., van Orten-Luiten, A.-C. B., Tigchelaar, E. F. et al. Dietary supplement use and colorectal cancer risk: a systematic review and meta-analyses of prospective cohort studies. Int J. Cancer 136, 2388-2401 (2015).

89. Smith, G. D. \& Egger, M. Meta-analyses of observational data should be done with due care. BMJ 318, 56 (1999). 